\title{
Self-Reports of Executive Dysfunction in Current Ecstasy/Polydrug Users
}

Florentia Hadjiefthyvoulou, $\mathrm{PhD},{ }^{1}$ John E. Fisk, $\mathrm{PhD},{ }^{2}$ Catharine Montgomery, $\mathrm{PhD},{ }^{3}$ and Nikola Bridges, $\mathrm{PhD}^{2}$

\author{
${ }^{1}$ Division of Psychology, Nottingham Trent University \\ ${ }^{2}$ School of Psychology, University of Central Lancashire \\ ${ }^{3}$ School of Natural Sciences \& Psychology, Liverpool John Moores University
}

Running head: Executive Dysfunction in Illicit Drug Users

\section{Corresponding author:}

Professor John E. Fisk, PhD

School of Psychology

University of Central Lancashire

Preston PR1 2HE

United Kingdom

Tel 44 (0) 1772894465

Fax 44 (0) 1772892925

e-mail: jfisk@uclan.ac.uk

The authors declare no conflicts of interest. All the authors contributed equally to the work. 


\section{Abstract}

Objectives/Background. Ecstasy/polydrug users have exhibited deficits in laboratory tests of executive functioning. We sought to extend these findings by investigating the extent to which ecstasy/polydrug users manifest executive deficits in everyday life. Methods. Fortytwo current ecstasy/polydrug users, 18 previous (abstinent for at least 6 months) ecstasy/polydrug users, and 50 non-users of ecstasy (including both non-users of any illicit drug and some cannabis-only users) completed the self-report Behavior Rating Inventory of Executive Function-Adult Version (BRIEF-A) measure. Results. Current ecstasy/polydrug users performed significantly worse than previous users and non-users on subscales measuring inhibition, self-monitoring, initiating action, working memory, planning, monitoring ongoing task performance, and organizational ability. Previous ecstasy/polydrug users did not differ significantly from nonusers. In regression analyses, although the current frequency of ecstasy use accounted for statistically significant unique variance on 3 of the 9 BRIEF-A subscales, daily cigarette consumption was the main predictor in the 6 other subscales. Conclusions. Current ecstasy/polydrug users report more executive dysfunction than do previous users and nonusers. This finding appears to relate to some aspect of ongoing ecstasy use and seems largely unrelated to the use of other illicit drugs. An unexpected finding was the association of current nicotine consumption with executive dysfunction.

Key Words: ecstasy, MDMA, BRIEF-A, executive function, cocaine 
Executive functions have been described as "a collection of correlated but separable control processes that regulate lower level cognitive processes to shape complex performance" (p 201). ${ }^{1}$ Executive functions are known to rely heavily on prefrontal cortical structures, most notably the dorsolateral prefrontal cortex. ${ }^{2}$ These functions underpin performance in a range of domains, thereby supporting the most cognitively demanding aspects of human behavior. ${ }^{3}$

A relatively new line of investigation evaluates the integrity of executive functioning in users of recreational drugs, specifically ecstasy, cannabis and cocaine The psychoactive ingredient in ecstasy 3,4-methylenedioxy-N-methylamphetamine, (MDMA) is known to have neurotoxic effects on serotonergic axon terminals in both animals and humans. ${ }^{4}$ In view of the important role that serotonin plays in regulating prefrontal neural processes, ${ }^{5}$ the possibility that executive processes are impaired in former and current ecstasy users deserves serious consideration. Most such assessment in the area of recreational drug use has been restricted to laboratory-based measures; a number of laboratory-based studies have demonstrated deficits among currently abstinent ecstasy users (see Murphy, Wareing, Fisk, et $\mathrm{al}^{6}$ for a review).

To supplement the insights gained from laboratory-based neuropsychological tests, investigators have developed self-report measures designed to evaluate an individual's dayto-day executive functioning in the real world. By offering environmental, contextual indicators of executive processes, self-report measures provide a useful complement to "snapshot" laboratory-based measures obtained during a single assessment.

One of the best established self-report measures is the Behavior Rating Inventory of Executive Function (BRIEF) ${ }^{7}$, which includes questions about everyday activities in familiar contexts that respondents can readily identify with. The BRIEF captures the behavioral manifestations of executive dysfunction in the interrelated behavioral domains commonly 
discussed in the literature. ${ }^{8}$ Each of the BRIEF's 9 subscales assesses a separate aspect of executive functioning. The 9 subscales are termed as Inhibit, Shift, Emotional Control, SelfMonitor, Initiate, Working Memory, Plan/Organize, Task Monitor, and Organization of Materials. The BRIEF has been used in a wide range of research, eg, attention deficit/ hyperactivity disorder, ${ }^{9-13}$ bipolar disorder, ${ }^{14}$ autism spectrum disorders, ${ }^{10,15-16}$ childhood epilepsy, ${ }^{17}$ frontal lobe lesions, ${ }^{18}$ and traumatic brain injury. ${ }^{10,19}$

Although laboratory tests are important in identifying impairments in executive processes, it is not always easy to draw inferences from the results about which specific aspects of everyday behavior may be adversely affected. The BRIEF's multidimensional nature and its ability to tap manifestations of executive functioning in everyday settings give us a more comprehensive view of executive deficits among young adults who use ecstasy and other illicit drugs recreationally.

Given that laboratory measures of executive function have shown ecstasy-related deficits, we predicted that ecstasy users would show impairment on at least some of the BRIEF subscales. Past research (eg, Wareing and co-workers ${ }^{20,21}$ ) has suggested that executive function deficits persist in former ecstasy users who have been abstinent for a long time. We predicted, therefore, that both current and previous ecstasy users would be equally susceptible to executive deficits.

\section{METHODS}

\section{Participants}

We evaluated 110 students who were attending the University of Central Lancashire or Liverpool John Moores University. We recruited using the "snowball technique," ie, wordof-mouth referral. ${ }^{22}$ Of the total participants, 42 (21 men, 21 women) were current 
ecstasy/polydrug users, 18 (4 men, 14 women) were previous ecstasy/polydrug users who had been abstinent for at least 6 months, and 50 (12 men, 38 women) were non-users of ecstasy; this last group included both non-users of any illicit drugs and some cannabis-only users. We defined polydrug use as the use of two or more psychoactive drugs. All of our ecstasy/polydrug users were users of ecstasy who also used other psychoactive drugs such as cannabis and cocaine. All of the participants consumed legal drugs such as alcohol, and a substantial minority smoked cigarettes (Table 1).

\section{$<<$ Insert Table 1 About Here $>>$}

\section{Procedures}

We informed the participants about the general purpose of the study and their right to withdraw at any time. After they gave their verbal consent to participate, they took the tests in a quiet laboratory. In order to protect the student's anonymity, written consent was not obtained. First we obtained data on their age, sex, years of education, and current use of alcohol and cigarettes. Alcohol consumption was measured in units, where, for example, a glass of wine, a single measure of spirits or a half a pint of beer is equivalent to one unit. Then we assessed their history of illicit drug consumption with a background drug-use questionnaire that has been used extensively in previous research (eg, Montgomery, Fisk, Newcombe, et $\mathrm{al}^{23}$ ). The responses enabled us to estimate total lifetime use for each drug (ecstasy, cannabis, cocaine, amphetamines, etc), frequency of use, and period of abstinence. We used Raven's Progressive Matrices ${ }^{24}$ to measure the participants' fluid intelligence. Then we gave this sequence of tests (each is described below): the EMQ, PRMQ, CFQ, and BRIEF-A.

The participants also completed a range of other laboratory-based measures, the results of which are beyond the scope of this study and are reported elsewhere. ${ }^{32,33}$ 
At the end of the experiment, the participants were fully debriefed, paid $£ 20 \mathrm{UK}$ in Tesco store vouchers, and given drug education leaflets. We handed them the CFQ for Others and asked them to give it to their relative, partner, or housemate to complete and return in a pre-paid addressed envelope. 44 completed questionnaires were returned.

The study was approved by the ethics committees of Liverpool John Moores University and the University of Central Lancashire.

\section{Self-Report Measures}

\section{Behavior Rating Inventory of Executive Function-Adult Version (BRIEF-A)._Many}

studies have shown the reliability and validity of the BRIEF in assessing executive functions. ${ }^{8,10,13,25-26}$ The BRIEF-A ${ }^{7}$ is a 75 -item measure of 9 aspects of executive function:

- Inhibit : ability to resist or control impulses (8 items), eg, "I tap my fingers or bounce my legs."

- Shift: ability to shift attention, change strategies, and act flexibly (6 items), eg, "I have trouble changing from one activity to another."

- Emotional Control: ability to control one's emotions (10 items), eg, "I have angry outbursts."

- Ability to Self-Monitor: sensitivity, ability to infer the feelings and emotions of others, and behaving in a thoughtful manner (6 items), eg, "I don't notice when I cause others to feel bad or get mad until is too late."

- Ability to Initiate: having the impetus to begin tasks, generate ideas, and develop strategies (8 items), eg, "I need to be reminded to begin a task even when I am willing."

- Working Memory: temporary storage and maintenance of information while working on ongoing tasks (8 items), eg, "I have trouble concentrating on tasks (such as chores, reading, or work)." 
- Ability to Plan/Organize: setting goals and developing tactics to achieve them, anticipating future events, and preparing strategies to deal with them (10 items), eg, "I get overwhelmed by large tasks."

- Task Monitor: ability to appraise task requirements and avoid making careless mistakes (6 items), eg, "I make careless errors when completing tasks."

- Organization of Materials: being organized and tidy (8 items), eg, "I am disorganized."

For each item, participants respond on a 3-point scale: Never (1 point), Sometimes ( 2 points), Often ( 3 points). For each of the 9 subscales, the scores for the relevant questions are combined to make the total score. Higher scores on each subscale indicate more executive dysfunction.

The 9 BRIEF-A subscales map onto 2 higher-level indices: the Behavioral Regulation Index and the Metacognition Index -. The Behavioral Regulation Index, a measure of a person's ability to maintain appropriate regulatory control of behavior and emotional responses, combines the first 4 BRIEF-A subscales: Inhibit, Shift, Emotional Control, and Self-Monitor. The Metacognition Index, a measure of a person's ability to solve different kinds of problems systematically through effective planning and organization, combines the 5 other BRIEF-A subscales: Initiate, Working Memory, Plan/Organize, Task Monitor, and Organization of Materials. The Behavioral Regulation Index and Metacognition Index, in turn, map onto a single total executive function score called the Global Executive Composite. As with the individual subscales, higher Behavioral Regulation Index, Metacognition Index, and Global Executive Composite scores indicate more executive dysfunction.

An additional 3 scales - infrequency, negativity, and inconsistency - measure the validity and reliability of the participant's responses. Infrequency is the extent to which a respondent endorses items that the vast majority of people reject (5 items), eg, "I forget my name." Scores on certain other items are combined to form indicators of 'negativity' and 
'inconsistency'. Negativity is the tendency to perceive oneself in an unduly negative manner, relative to the norm. Inconsistency is the tendency to give different answers to similar questions. High scores on any of these 3 scales potentially compromise the BRIEF-A's validity.

Everyday Memory Questionnaire (EMQ). The EMQ ${ }^{27,28}$ is a self-report measure of memory lapses in everyday activities. The measure consists of 27 statements like "forgetting where you put something" and "finding a television story difficult to follow." Participants respond on a 9-point scale ranging from "not at all in the last 6 months" to "more than once a day." The total score is the sum of responses on all items.

Cognitive Failures Questionnaire (CFQ). The $\mathrm{CFQ}^{29}$ is a 25 -item measure of everyday attentional deficits, with questions like "Do you fail to notice signposts on the road?" and "Do you start doing one thing at home and get distracted into doing something else?" Participants respond on a 5-point scale with zero being "never" and 4 being "very often." The maximum score is 100 .

Cognitive Failures Questionnaire (CFQ) for Others. To assess the accuracy of our participants' responses, we asked them to give the CFQ for Others ${ }^{29}$ to a "significant other," ie, someone who had a reasonable knowledge of the participant's real-world behavior. In the original study of the CFQ for Others, Broadbent et al surveyed participants' family members or partners, but because we were studying a student population, we followed Smith-Spark et $\mathrm{al}^{30}$ and considered a "housemate" to be a significant other. The respondent was asked to complete the questionnaire and return it to us in a pre-paid addressed envelope. 
Each of the 8 questions started with, "During the last six months has your relative/partner/housemate seemed to be..." The question then asked about a different type of behavior, eg, "disorganized, that is, getting into a muddle when doing something because of lack of planning or concentration?" The respondent selected one of the following responses: Very Often (5 points), Quite Often (4 points), Occasionally (3 points), Very Rarely (2 points), Never (1 point). For half of the questions, these response alternatives were listed underneath from left to right, for the other half they were listed underneath from right to left. The total score is the sum of the individual item scores (maximum 40) with a high score indicative of more cognitive failures.

Prospective and Retrospective Memory Questionnaire (PRMQ). The $\mathrm{PRMQ}^{31}$ is a measure of memory slips. Half of its 16 items ask about prospective memory failures, and half about retrospective failures, eg, "Do you fail to recall things that have happened to you in the last few days?" Participants say how often these things have happened to them, using a 5point scale: five being "very often", four being "quite often", three being "sometimes", two being "rarely", or one being "never". Scores can range from 8 to 40. For our study, we used only the retrospective memory scores.

\section{Statistical Design}

As dependent variables, we used the 9 subscales of the BRIEF-A. The independent variable was drug use with three levels (current ecstasy user, previous ecstasy user, and nonuser of ecstasy). Covariates were alcohol and cigarette smoking. 
We conducted regression analyses with the BRIEF-A subscales as dependent variables and, as independent variables, the current frequency of ecstasy, cannabis, and cocaine use and current cigarette and alcohol use.

We ran correlations between the BRIEF-A measures (the subscales and the higherorder executive function composites) and the periods of abstinence for ecstasy, cannabis, and cocaine.

We ran partial correlations between the BRIEF-A scores and the measures of everyday memory, self-reported retrospective memory, and cognitive failures. The selfreported memory measures and cognitive failures served as controls in successive analyses.

\section{RESULTS}

Using the criteria suggested by Tabacknick and Fidell, ${ }^{34}$ we found no univariate outliers. One multivariate outlier was identified and excluded from further analysis. The BRIEF-A validity subscales for infrequency, negativity, and inconsistency did not reveal any response patterns that might justify excluding a participant. Thus, we were able to analyze the data on all 110 participants. We also found that the distribution of the BRIEF-A subscale scores did not deviate significantly from normal. In relation to skewness and kurtosis, the zscores associated with the statistics were all less than $3, P>0.001$ in all cases, which is consistent with normality for samples of this size. ${ }^{34}$

On their background demographics and use of legal drugs, the 3 study groups differed significantly only in their alcohol use (Table 1). Tukey's post-hoc test revealed that only 1 of the pairwise comparisons was statistically significant: current ecstasy/polydrug users consumed significantly more units of alcohol per week than non-users of ecstasy, $P=$ 0.007. During the previous three months, 7 of the current ecstasy users, reported occasionally 
using amphetamine, 2 DOB (2,5-Dimethoxy-4-bromoamphetamine,) 13 ketamine, and 4 LSD. Similarly, 3 of the previous ecstasy users reported occasionally using ketamine and 1 , LSD. In addition to ecstasy, the most frequently used illicit drugs were cannabis and cocaine. Table 2 shows the 3 groups' use of these drugs. Among the non-users of ecstasy, illicit drug use was largely restricted to cannabis (1 person reported occasional use of ketamine). Although there were group differences in cannabis and cocaine use, few reached statistical significance. However, the groups had marked differences in their periods of abstinence from all 3 illicit drugs. The non-ecstasy users had abstained significantly longer than current users from cannabis and previous ecstasy users had abstained significantly longer than current users from both cocaine and obviously from ecstasy.

\section{$<<$ Insert Table 2 About Here $>>$}

Table 3 shows the outcomes (means and s.d.) for the BRIEF-A subscales for each of the three groups. With the exceptions of Shift and Emotional Control, the BRIEF subscales showed the current ecstasy/polydrug users performing worse (as indicated by a higher score) than the previous users and non-users. The better (lower) scores in the previous users and non-users were similar to one another. Multivariate analysis of variance, with the BRIEF-A subscale scores as dependent variables, and with drug use between participants and current cigarette and alcohol consumption as covariates, revealed a statistically significant multivariate group effect, $\Lambda=.697, \mathrm{~F}(18,186)=2.04, P<0.01$, partial $\eta^{2}=.165$. With the 2 exceptions of Shift and Emotional Control, subsequent univariate analyses, reported in Table 3, revealed that the group effect was statistically significant for each of the individual BRIEFA subscales.

\section{$<<$ Insert Table 3 About Here $>>$}

We had predicted that both current and previous ecstasy/polydrug users would score significantly worse than non-users on measures of executive function. For current users, 7 of 
the 9 pairwise comparisons (based on the least significant difference test) confirmed our prediction. However, our prediction did not prove true for previous users. In fact, the previous users and non-users did not differ significantly on any of the comparisons. It is also noteworthy that the previous users scored significantly better than the current users on 7 of the 9 BRIEF-A subscales. These pairwise comparisons remained significant after Bonferroni correction at the adjusted alpha level of $.016(\approx .05 / 3)$.

As for the covariates, daily consumption of cigarettes was associated with a statistically significant multivariate effect, $\Lambda=.758, \mathrm{~F}(9,93)=3.30, P<0.01$, partial $\eta^{2}=.242$. Furthermore, all 9 of the univariate analyses produced statistically significant cigarette covariate effects: for Inhibit and Self-Monitor, $P<0.001$; for Emotional Control, Working Memory, and Plan/Organize, $P<0.01$; and for Shift, Initiate, and Task Monitor, $P<0.05$. Neither the multivariate nor the univariate alcohol-related covariate effects were statistically significant, $P>0.05$ in all cases.

Because previous ecstasy users scored as unimpaired on the BRIEF-A, impaired executive function seems to be related to some aspect of current drug use. In addition to ecstasy, many current users were regularly consuming cocaine and cannabis. It is possible that any of these 3 drugs was responsible for the users' impairment. Nicotine or alcohol might also have contributed.

To examine these possibilities, we conducted 9 multiple regression analyses with the BRIEF-A subscales as dependent variables. In each analysis, the independent variables were the current frequency of ecstasy, cannabis, and cocaine use; the number of units of alcohol consumed per week; and the number of cigarettes smoked per day. The results of these analyses are shown in Table 4. For each regression, the table contains the standardized beta weight, simple correlation, and semipartial correlation for each predictor. For the simple correlations, the current frequencies of ecstasy, cocaine, and cannabis use correlated 
significantly with a number of the BRIEF-A subscales. For example, frequency of ecstasy was significantly correlated with the Inhibit, Self-Monitor, Initiate, Plan/Organize and Task Monitor subscales. Frequency of cocaine was significantly correlated with the Inhibit, SelfMonitor, Initiate and Plan/Organize subscales and frequency of cannabis was significantly correlated with the Initiate subscale. Frequency of ecstasy use was also significantly correlated with the higher-order Behavioral Regulation and Metacognition Indices as well as the Global Executive Composite score while frequency of cocaine use was significantly correlated with the Metacognition Index. In the regression analyses, the frequency of ecstasy use was statistically significant in the models for the Inhibit, Self-Monitor, and Task Monitor BRIEF-A subscales and for the higher-order Behavioral Regulation and Global Executive Composite BRIEF-A scales. The current frequencies of cocaine and cannabis use were not statistically significant as predictors in any of the regression equations.

\section{$<<$ Insert Table 4 About Here $>>$}

What we had not predicted was the association between daily cigarette smoking and impaired executive function. This predictor, daily cigarette smoking, was statistically significant in 8 of the 9 the regressions for the BRIEF-A subscales. Smoking was also a significant predictor in the regression equations for the higher-order Behavioral Regulation, Metacognition, and Global Executive Composite BRIEF-A scales. Of note, for 6 of the BRIEF-A subscales, the cigarettes per day predictor was associated with the largest semipartial correlation coefficient, indicating that it accounted for the largest proportion of unique variance in the dependent variables For the remaining predictor, units of alcohol per week, a number of the simple correlations with the BRIEF-A measures were statistically significant. For instance, units of alcohol per week was significantly correlated with the Inhibit, Self-Monitor, Initiate, Plan/organize, Task Monitor and organization of materials subscales of the BRIEF-A as well as with the high-order Metacognition Index and Global 
Executive Composite scales. However, weekly alcohol consumption was statistically significant in only 1 of the regression equations, that for the Plan/Organize BRIEF-A subscale.

Although the number of cigarettes per day was clearly important as a predictor, the current ecstasy/polydrug users were impaired relative to the other groups even after we controlled for nicotine consumption in our analysis. However, Table 2 makes it clear that the previous ecstasy users not only had ceased using ecstasy but also had not consumed cocaine or cannabis for a long time. Indeed, the group difference for "weeks since last use" for these 2 drugs was statistically significant. Similarly, the current ecstasy/polydrug users had a shorter period of abstinence for cannabis than did the other 2 groups; again, the overall group difference was statistically significant. It is possible, therefore, that the group differences observed in the current users' executive functioning might be a result of the effects of cannabis or cocaine rather than ecstasy.

To examine this possibility, we correlated the period of abstinence for the 3 major illicit drugs with the BRIEF-A subscales and the higher- order BRIEF-A scales. As shown in Table 5, only the period of abstinence from ecstasy correlated significantly with the executive function measures. Table 5 also reveals that, with just 1 exception, ecstasy, cocaine, and cannabis consumption during the previous 10 days was unrelated to the BRIEF-A outcomes. Thus, the current users' findings for executive dysfunction do not reflect a short-term postintoxication effect.

\section{$<<$ Insert Table 5 About Here $>>$}

The current users' BRIEF-A scores could reflect some self-perceived general cognitive deficit, perhaps in everyday memory processes, rather than a specific executive function deficit. This would potentially compromise the validity of the BRIEF-A and therefore it would be desirable to attempt to disconfirm this possibility. In our previous 
studies, ${ }^{32,33}$ the same participants completed self-report measures of their real world memory functioning - the EMQ, PRMQ, and CFQ — and their partners or roommates completed the CFQ for Others to give an external assessment. Although all 4 of these questionnaires tap processes that reflect prefrontal and medial temporal functions, the CFQ and CFQ for Others relate primarily to the efficacy of executive processes, ${ }^{35}$ the retrospective memory subscale of the PRMQ assesses the efficacy of recall in everyday contexts, ${ }^{36}$ and the EMQ contains questions that reflect both executive and medial temporal processes. ${ }^{37}$ Though the BRIEF-A subscales might be expected to correlate with all 4 of these measures, the correlation with the CFQ should be particularly robust given that both the BRIEF-A and the CFQ primarily reflect behaviors associated with executive processes.

Thus if the BRIEF-A does primarily relate to executive processes then when the variance associated with more basic memory processes (as reflected in the EMQ and the PRMQ) is removed then the partial correlations between the BRIEF-A and the CFQ should remain statistically significant since both these measures predominantly reflect executive processes. However when the variance associated with executive processes (as reflected in the CFQ) is removed the partial correlations between the BRIEF-A and the more basic memory measures, should no longer be statistically significant since any residual variance associated with executive processes in the EMQ and the PRMQ should have been removed. Table 6 shows correlations and partial correlations between the BRIEF-A measures and the other self-report measures of real-world memory. With the exception of the Shift and Emotional Control, all other 7 subscales of the BRIEF-A and the higher-order Behavioral and Metacognition Indices and Global Executive Composite scales were correlated with all of the other real-world memory measures. Controlled for individual differences in simple recall and memory functions as reflected in the EMQ and PRMQ, most of the correlations between the BRIEF-A and the CFQ remained statistically significant, reflecting the fact that both 
measures concern executive functions. Partial correlations controlling for the CFQ would essentially remove the executive element from the other measures. When we controlled for the CFQ, the BRIEF-A no longer correlated significantly with the EMQ and the retrospective memory subscale of the PRMQ (Table 6, columns 5 and 7). It seems possible, therefore, that all 5 scales reflect, at least to some degree, self-perceptions of executive function or perhaps some general conception of cognitive capacity. However, it appears that the BRIEF-A, CFQ, and CFQ for Others relate primarily to executive functions, and the EMQ and the retrospective memory subscale of the PRMQ primarily reflect nonexecutive processes such as recall and learning.

\section{$<<$ Insert Table 6 About Here $>>$}

The first column of Table 6 contains the correlations between the CFQ for Others and the BRIEF-A. Interestingly, all but 2 of the BRIEF-A subscales correlated significantly with the CFQ for Others, implying that the participants' own assessment of their executive functions has at least some overlap with the assessment of their significant other.

\section{DISCUSSION}

Current ecstasy/polydrug users performed significantly worse than previous users and non-users on 7 of 9 BRIEF-A subscales, the exceptions being Emotional Control and Shift. The impairment was restricted to current ecstasy users; previous users showed no sign of executive dysfunction, performing similarly to nonusers. The current frequency of ecstasy use was significantly related to the executive function measure, with increasing frequency of use associated with worse BRIEF-A scores. Regression analyses revealed that the current frequency of ecstasy use accounted for statistically significant unique variance on 3 of the BRIEF-A subscales as well as the BRIEF-A higher-order Behavioral Regulation Index and the Global Executive Composite score. 
Neither cannabis nor cocaine was associated with statistically significant unique variance on any of the BRIEF-A measures. The extent of executive dysfunction among the ecstasy users diminished with longer abstinence from the drug. However, executive function was unrelated to use of the 3 major illicit drugs - ecstasy, cannabis, and cocaine - within the previous 10 days. Thus, the perceived deficits were not restricted to participants with recent exposure to the drugs.

In terms of the effect sizes from the analyses of variance, the ecstasy-related difference was greatest for the BRIEF-A Inhibit subscale, for which we found an effect size of $21 \%$ (partial $\eta^{2}=.208$ ). The effect sizes for the Self-Monitor, Task Monitor, and Initiate subscales ranged between $12.5 \%$ and $14.2 \%$. For the remaining subscales, effect sizes were below $10 \%$. The emergence of an ecstasy-related effect on the Inhibit subscale seems at first to be at odds with laboratory studies (eg, Montgomery et $\mathrm{al}^{23}$ ) whose tests of inhibitory function failed to reveal ecstasy-related deficits. However, the BRIEF-A Inhibit scale covers aspects of impulsivity such as the propensity for fidgeting, restlessness, impatience, and distractibility. By contrast, laboratory tests focus on the ability to inhibit previously learned prepotent responses, as in the Stroop paradigm or random generation. ${ }^{38}$

The BRIEF-A Task Monitor and Initiate subscales are associated with the ability to formulate and maintain goal-directed behavior-more specifically, the ability to initiate appropriate action sequences and to develop subgoals, monitor progress, and focus attention in a task-centered manner. Laboratory studies have shown that ecstasy users have problems updating the contents of their working memory (see Murphy et $\mathrm{al}^{7}$ for a review), failing to delete information that is no longer relevant, and being unable to incorporate new information effectively. They also seem to be less successful in accessing the contents of their semantic memory. Our study suggests that in the real world these problems may manifest themselves as an inability to maintain goal-directed behavior, and a tendency for impulsivity. 
One of the laboratory tasks involving goal-directed behavior is the Tower of London Test. When ecstasy users have taken this test, the results have been mixed: Morgan ${ }^{39}$ failed to find any evidence of ecstasy-related impairment, but Fox et $\mathrm{al}^{40}$ found that ecstasy users took significantly longer to plan their initial moves on the task. Our results suggest that in the real world, where people face many distractions and interruptions, current ecstasy users might have impairments in the initiation and maintenance of goal-directed behavior.

The existing evidence on impulsivity is also somewhat inconsistent, with some studies finding that ecstasy users perceive themselves to be more impulsive then nonusers on selfreport measures but do not exhibit this tendency in laboratory tests (eg, Clark, Roiser, Robbins, et $\mathrm{al}^{41}$ ), and other studies observing the opposite tendencies (eg, Schilt, Goudriaan, Koeter, et $\mathrm{al}^{42}$ ). Moeller, Dougherty, Steinberg, et $\mathrm{al}^{43}$ found that heavy ecstasy users exhibited impulsivity on both self-report and laboratory measures. Likewise, elevated impulsivity was evident among heavy ecstasy users in the Quednow, Kühn, Hoppe, et al ${ }^{44}$ laboratory study. Morgan et $\mathrm{al}^{39,45}$ also found ecstasy users to have high levels of impulsivity on laboratory measures compared to nonusers. Our results suggest that ecstasy/polydrug users report problematic behaviors in real-world contexts stemming from their heightened impulsivity, but that this tendency diminishes as they abstain for longer periods.

The BRIEF-A Self-Monitor subscale, on which our current ecstasy users also exhibited impairment, concerns the ability to understand the feelings of others and to anticipate the consequences of one's actions. These types of behavior are believed to be supported by the orbitofrontal cortex. Indeed, Mah, Arnold, and Grafman ${ }^{46}$ found that social and interpersonal perception was impaired in people with orbitofrontal lesions. Similarly, Beer, John, Scabini, et $\mathrm{al}^{47}$ found that patients with orbitofrontal lesions exhibited inappropriate social behavior and that their actions were associated with impaired selfmonitoring ability. Neuroimaging studies of cocaine-dependent individuals have shown 
decreased gray-matter volume in various cortical structures, including the orbitofrontal cortex, with the extent of the reduction related to the duration of cocaine dependence. ${ }^{48}$

In our study, outcomes on the BRIEF-A Self-Monitor subscale were largely unrelated to cocaine use. Although the frequency of cocaine use correlated significantly with selfmonitoring performance, the cocaine measure failed to reach statistical significance in the corresponding regression equation. Our results implicate current ecstasy use as being associated with impaired self-monitoring. Some neuroimaging research links ecstasy use with reduced serotonin transporter densities in the orbitofrontal cortex; however, other brain regions have also exhibit similar or more severe reductions. ${ }^{49}$

Our ecstasy/polydrug users performed normally on the BRIEF-A Emotional Control subscale. At first sight, this outcome is at odds with the results of Reay et al, ${ }^{50}$ who found that ecstasy users were impaired on a measure of emotional intelligence. However, the BRIEF-A Emotional Control subscale covers primarily the personal expression of emotions, eg, the ability to control one's temper. Emotional intelligence is a far broader construct that is more concerned with reading emotions in other people and acting appropriately. Interestingly, these aspects of emotional competence form part of the BRIEF-A Self-Monitor subscale, which, as noted earlier, addresses the ability to understand the feelings of others and to anticipate the consequences of one's actions. As our ecstasy users were impaired on this subscale, our results are broadly consistent with those of Reay et al.

An unanticipated finding of our study was the association of daily cigarette smoking with executive dysfunction. There is evidence that neural processing is adversely affected in abstinent smokers. For example, $\mathrm{Xu}$, Mendrek, Cohen, et $\mathrm{al}^{51}$ found that, when performing an n-back task, left dorsolateral prefrontal cortex activity was higher in smokers who had abstained for a minimum of 14 hours compared to those who had smoked recently, even in conditions with low task load, and did not increase with higher loads. By contrast, activity 
was lower in participants who had smoked recently, and increased with task load. The authors interpreted their results as indicating less efficient neural processing during short-term abstinence from nicotine. In a subsequent fMRI study by the same authors, smoking a cigarette after a period of abstinence (13 hours) increased neural processing efficiency, although smoking a cigarette in a satiated condition did not have this effect. ${ }^{52}$

Temporary cessation from smoking thus appears to compromise neural function, presumably as a consequence of nicotine withdrawal. Consistent with this finding, abstinent smokers taking nicotine lozenges performed better than those taking placebo on tasks measuring executive functions, working memory, and attention. ${ }^{53}$

It is also possible that regular smoking adversely affects executive function whether or not the individual is abstinent. For example, Jacobsen et $\mathrm{al}^{54}$ compared adolescent daily smokers with adolescent nonsmokers on tests of verbal memory and learning, verbal working memory, and attention. The investigators controlled for group differences in cannabis and alcohol use, baseline affect, intelligence, reading skill, age, sex, and parental education. The smokers were impaired on tests of working memory whether or not they had smoked recently, and the impairment was worse in those who had started smoking at an earlier age. During abstinence deficits in working memory were exacerbated and deficits in verbal memory also became apparent.

In a later fMRI study by Jacobsen and colleagues, ${ }^{55}$ abstinent adolescent smokers performing a high-load executive function task had greater activation than non-smokers in specific areas known to support verbal working memory, such as the left ventrolateral prefrontal cortex and the left inferior parietal lobe. As task demands increased, the abstinent smokers did not display the non-smokers' increase in functional connectivity across the neural circuits supporting working memory processes. The authors attributed their findings to 
the heightened neurotoxic potential of nicotine when tobacco is consumed earlier in adolescent development.

It is unclear whether the adverse effects of smoking persist long-term. In a middleaged sample, women (but not men) diagnosed with a history of tobacco dependence performed worse than those without such a diagnosis on measures of processing speed, visuospatial processing, and executive functioning. ${ }^{56}$ In a sample with an average age older than 67 , most aspects of cognitive functioning were unaffected by a history of smoking, but heavy smokers performed worse than light and moderate smokers on the Wisconsin Card Sorting Test ${ }^{57}$ By contrast, Schinka, Vanderploeg, Rogish, et $\mathrm{al}^{58}$ studied people aged 60 to 84 and failed to find any effects of lifelong smoking history on executive and other cognitive functions. However, in a sample of men with and without a history of alcoholism, Glass, Buu, Adams, et $\mathrm{al}^{59}$ found that estimates of lifetime smoking were negatively associated with executive functioning, particularly on tasks with a processing speed component.

Smoking-related impairment in self-reported executive functioning is a cause for concern, at least for current smokers during periods of abstinence. Now that many places ban indoor smoking, it is likely that learning and memory will be adversely affected. This is a particular concern for people in higher education, like our student study participants, and more generally for people engaged in cognitively demanding activities.

Our study had some limitations. As with most studies in this field, ours had no objective measure of drug use, such as urinalysis or hair analysis; such a measure would have been desirable to confirm participants' self-reports. Another consideration is that the selfreported apparent ecstasy/polydrug-related deficits may not have been a direct consequence of illicit drug use, but rather of differences between users and nonusers predating their illicit drug use. Although pre-existing differences between study groups are clearly a possibility, the absence of deficits among the previous ecstasy users might cast some doubt on this 
explanation. It is also possible that the effects that we observed in our current users were related to lifestyle differences or to the physiological effects of illicit drug use, such as impaired sleep quality, ${ }^{60}$ rather than having a direct pharmacological basis.

Although the psychometric integrity of the BRIEF-A has been documented, our results further confirm its validity. Our participants completed not only the BRIEF-A but also the CFQ, which is believed to reflect executive processes, and the PRMQ and EMQ, which reflect more basic memory processes and other more general aspects of everyday cognition. After controlling for other real-world memory measures, we found that the BRIEF-A shared unique variance with the CFQ . Given that the CFQ is believed to reflect executive processes, our finding suggests that the BRIEF-A does indeed selectively capture this aspect of cognitive functioning. Furthermore, when the executive component of the other real-world memory measures, the PRMQ and EMQ, was attenuated by our controlling for individual differences on the CFQ, the correlations between these measures and the BRIEF-A scores were no longer statistically significant. Thus, the BRIEF-A seems to reflect executive processes rather than the more basic memory functions tapped by the PRMQ and EMQ. It is also noteworthy that our participants' BRIEF-A scores correlated with the CFQ for Others ratings, implying that the participants' own assessment of their executive functions has some degree of overlap with the assessment of their significant other.

Given that the BRIEF-A has been shown to share variance with these other self-report measures, we should point out that ecstasy/polydrug-related deficits have also been observed on the CFQ, EMQ, and PRMQ. For example, Montgomery and Fisk ${ }^{61}$ found that ecstasy/polydrug users reported more everyday memory problems than did non-users on the EMQ, and more cognitive failures on the CFQ. More recently, Hadjiefthyvoulou et $\mathrm{al}^{32}$ found that ecstasy/polydrug users were impaired on the EMQ and that the effect remained significant after controlling for cannabis, alcohol, and nicotine use. In the same study, 
although the overall group effect was not significant for the CFQ, cognitive failures were positively associated with lifetime ecstasy consumption and current frequency of use. Lastly, although the PRMQ has received less attention in the substance abuse literature than other measures, a recent study ${ }^{33}$ found that ecstasy/polydrug users were also impaired on this measure. The fact that illicit drug users are impaired on the BRIEF-A and these other measures of real-world memory is consistent with the proposition that, to some degree, all the measures reflect the operation of executive resources.

To conclude, we intended to determine the impact of ecstasy/polydrug use on executive function using the self-report BRIEF-A. Our current ecstasy/polydrug users performed significantly worse than long-term abstinent previous users and non-users on 7 of 9 BRIEF-A subscales, the exceptions being the ability to shift mental set and to regulate emotions. The current frequency of ecstasy use accounted for significant unique variance on the Inhibit, Self-Monitor, and Task Monitor subscales and on the Behavioral Regulation and overall composite higher order scales. An unanticipated finding was the association of daily cigarette smoking with executive dysfunction. 


\section{References}

1. Friedman NP, Miyake A, Young SE, et al. Individual Differences in Executive Functions Are Almost Entirely Genetic in Origin. J Exp Psychol Gen. 2008; 137: $201-225$.

2. Collette F, Van der Linden M, Laureys S. Exploring the unity and diversity of the neural substrates of executive functioning. Hum Brain Mapp. 2005; 25:409-423.

3. Smith EE, Jonides J. Storage and executive processes in the frontal lobes. Science 1999. 283:1657-1661.

4. Green AR, Mechan AO, Elliott JM, et al. The pharmacology and clinical pharmacology of 3,4-methylenedioxymethamphetamine (MDMA, "ecstasy"). Pharmacol Rev 2003; 55:463-508.

5. Morgan MJ. Ecstasy (MDMA): a review of its possible persistent psychological effects. Psychopharmacology (Berl) 2000; 152:230-248.

6. Murphy PN, Wareing M, Fisk JE, et al. Executive Working Memory Deficits in Abstinent Ecstasy/MDMA Users: A Critical Review. Neuropsychobiology 2009; 60:159-175.

7. Roth RM, Isquith PK, Gioia GA. Behavior Rating Inventory of Executive Function Adult Version. Odessa, Fla.: Psychological Assessment Resources, Inc, 2005.

8. Bodnar LE, Prahme MC, Cutting LE, et al. Construct validity of parent ratings of inhibitory control. Child Neuropsychol 2007; 13:345-362.

9. Chang W, Davies PL. Gavin WJ. Error monitoring in college students with attentiondeficit/hyperactivity disorder. J Psychophysiol 2009; 23:113-125.

10. Gioia GA, Isquith PK, Kenworthy L,et al. Profiles of everyday executive function in acquired and developmental disorders. Child Neuropsychol 2002; 8:121-137. 
11. Jarratt KP, Riccio CA, Siekierski BM. Assessment of attention deficit hyperactivity disorder (ADHD) using the BASC and BRIEF. Appl Neuropsychol 2005; 12:83-93.

12. Mahone EM, Hoffman J. Behavior rating of executive function among preschoolers with ADHD. Clin Neuropsychol, 2007; 21:569-586.

13. Toplak ME, Bucciarelli MS, Jain U, et al.. Executive Functions: Performance-Based Measures and the Behavior Rating Inventory of Executive Function (BRIEF) in Adolescents with Attention Deficit/Hyperactivity Disorder (ADHD). Child Neuropsychol 2009; 15:53-72.

14. Shear PK, DelBello MP, Rosenberg HL, et al. Parental reports of executive dysfunction in adolescents with bipolar disorder. Child Neuropsychol 2002; 8:285295.

15. Gilotty L, Kenworthy L, Sirian L, et al. Adaptive skills and executive function in autism spectrum disorders. Child Neuropsychol 2002; 8:241-248.

16. Chan AS, Cheung MH, Yvonne MY, et al. Executive function deficits and neural discordance in children with autism spectrum disorders. Clin Neurophysiol 2009; 120:1107-1115.

17. Sherman EMS, Slick DJ, Eyrl KL. Executive Dysfunction Is a Significant Predictor of Poor Quality of Life in Children with Epilepsy. Epilepsia 2006; 47:1936-1942.

18. Malloy P, Grace I. A review of rating scales for measuring behavior change due to frontal systems damage. Cogn Behav Neurol 2005; 18:18-27.

19. Gioia GA, Isquith PK. Ecological assessment of executive function in traumatic brain injury. Dev Neuropsychol 2004; 25: 135-158.

20. Wareing M, Fisk JE, Murphy P, et al. Verbal working memory deficits in current and previous users of MDMA. Hum Psychopharm Clin 2004; 19:225-234. 
21. Wareing M, Fisk JE, Murphy P, et al. Visuo-spatial working memory deficits in current and former users of MDMA ('Ecstasy'). Hum Psychopharm Clin, 2005; 20:115-123.

22. Solowij N, Hall W, Lee N. Recreational MDMA use in Sydney: a profile of ecstasy users and their experiences with the drug. Br J Addiction 1992; 87:1161-1172.

23. Montgomery C, Fisk JE, Newcombe R, et al. The differential effects of ecstasy/polydrug use on executive components: Shifting, inhibition, updating and access to semantic memory. Psychopharmacology (Berl) 2005; 182:262-276.

24. Raven J, Raven JC, Court JH. Manual for Raven's progressive matrices and vocabulary scales. Oxford Psychologists Press, Oxford, UK, 1998.

25. Rabin LA, Roth RM, Isquith PK, et al. Self- and informant reports of executive function on the BRIEF-A in MCI and older adults with cognitive complaints. Arch Clin Neuropsych 2006; 21:721-732.

26. Slick DJ, Lautzenhiser A, Sherman EMS, et al. Frequency of scale elevations and factor structure of the Behavior Rating Inventory of Executive Function (BRIEF) in children and adolescents with intractable epilepsy. Child Neuropsychol, 2006; 12 , 181-189.

27. Cornish IM. Factor structure of the Everyday Memory Questionnaire. Brit J Psychol, $2000 ; 91: 427-438$.

28. Sunderland A, Harris JE, Baddeley AD. Do laboratory tests predict everyday memory? J Verb Learn Verb Beh, 1983; 22:341-357.

29. Broadbent DE, Cooper PF, FitzGerald P, et al. The Cognitive Failure Questionnaire (CFQ) and its correlates. Brit J Clin Psychol 1982; 21:1-16.

30. Smith-Spark JH, Fawcett A, Nicolson RI, et al. Dyslexia and everyday cognitive performance. Memory 2004; 12:174-182. 
31. Crawford JR, Smith G, Maylor EA, et al. The prospective and retrospective memory questionnaire, (PRMQ): Normative data and latent structure in a large non-clinical sample. Memory 2003; 11:261-275.

32. Hadjiefthyvoulou F, Fisk JE, Montgomery C, et al. Everyday and prospective memory deficits in ecstasy/polydrug users. J Psychopharmacol 2011; 25:453-464.

33. Hadjiefthyvoulou F, Fisk JE, Montgomery C, et al. Prospective Memory Functioning among Ecstasy/Polydrug users: Evidence from the Cambridge Prospective Memory Test (CAMPROMPT). Psychopharmacology (Berl) 2011; 215:761-774.

34. Tabachnick BG, Fidell LS. Using Multivariate Statistics (Fifth Edition). Boston, Allyn and Bacon, 2007.

35. Righi S, Mecacci L, Viggiano MP. Anxiety, cognitive self-evaluation and performance: ERP correlates. J Anxiety Disord 2009; 23:1132-1138.

36. Eschen A, Martin M, Gasser US, et al. Prospective and retrospective memory complaints in mild cognitive impairment and mild Alzheimer's disease. Brain Impair $2009 ; 10: 59-75$.

37. Bjørnebekk A, Westlye LT, Walhovd KB, et al. Everyday memory: Self-perception and structural brain correlates in a healthy elderly population. J Int Neuropsych Soc $2010 ; 16: 1115-1126$.

38. Miyake A, Friedman NP, Emerson MJ, et al. The unity and Diversity of executive functions, and their contributions to complex "frontal lobe" tasks: A latent variable analysis. Cognitive Psychol 2000; 41:49-100.

39. Morgan MJ. Recreational use of 'ecstasy' (MDMA) is associated with elevated impulsivity. Neuropsychopharmacology, 1998; 19:252-264.

40. Fox HC, Parrott AC, Turner JJD. Ecstasy use: cognitive deficits related to dosage rather than self-reported use of the drug. J Psychopharmacol 2001; 15:273-281. 
41. Clark L, Roiser JP, Robbins TW, et al. Disrupted 'reflection' impulsivity in cannabis users but not current or former ecstasy users. J Psychopharmacol 2009; 23:14-22.

42. Schilt T, Goudriaan AE, Koeter MW, et al. Decision making as a predictor of first ecstasy use: A prospective study. Psychopharmacology (Berl) 2009; 203:519-527.

43. Moeller FG, Dougherty DM, Steinberg JL, et al. Heavy 'ecstasy' use is associated with increased impulsivity. Addict Disord Their Treat, 2002; 1:47-52.

44. Quednow BB, Kühn K-U, Hoppe C. et al. Elevated impulsivity and impaired decision-making cognition in heavy users of MDMA ('Ecstasy'). Psychopharmacology (Berl) 2007;189:517-530.

45. Morgan MJ. Impallomeni LC, Pirona A Rogers RD. Elevated impulsivity and impaired decision-making in abstinent ecstasy (MDMA) users compared to polydrug and drug-naïve controls. Neuropsychopharmacology 2006; 31:1562-1573.

46. Mah L, Arnold MC, Grafman J. Impairment of social perception associated with lesions of the prefrontal cortex. Am J Psychiatry 2004; 161:1247-1255.

47. Beer JS, John OP, Scabini D, et al. Orbitofrontal Cortex and Social Behavior: Integrating Self-monitoring and Emotion-Cognition Interactions. J Cogn Neurosci $2006 ; 18: 871-879$.

48. Ersche KD, Barnes A, Jones PS, et al. Abnormal structure of frontostriatal brain systems is associated with aspects of impulsivity and compulsivity in cocaine dependence. Brain 2011; 134:2013-2024.

49. McCann UD, Szabo Z, Vranesic M, et al. Positron emission tomographic studies of brain dopamine and serotonin transporters in abstinent $( \pm) 3,4-$ methylenedioxymethamphetamine ('ecstasy') users: Relationship to cognitive performance. Psychopharmacology (Berl) 2008; 200:439-450. 
50. Reay JL, Hamilton C, Kennedy DO, et al. MDMA polydrug users show processspecific central executive impairments coupled with impaired social and emotional judgement processes. J Psychopharmacol 2006; 20:385-388.

51. $\mathrm{Xu}$ J, Mendrek A, Cohen MS, et al. Brain activity in cigarette smokers performing a working memory task: Effect of smoking abstinence. Biol Psychiatry 2005; 58:143150.

52. Xu J, Mendrek A, Cohen MS, et al. Effects of acute smoking on brain activity vary with abstinence in smokers performing the N-Back Task: A preliminary study. Psychiatry Res 2006; 148:103-109.

53. Atzori G, Lemmonds CA, Kotler ML, et al. Efficacy of a nicotine (4 mg)-containing lozenge on the cognitive impairment of nicotine withdrawal. J Clin Psychopharmacol 2008; 28: 667-674.

54. Jacobsen LK, Krystal JH, Mencl WE, et al. Effects of Smoking and Smoking Abstinence on Cognition in Adolescent Tobacco Smokers. Biol Psychiatry 2005; $57: 56-66$.

55. Jacobsen LK, Mencl WE, Constable RT, et al. Impact of smoking abstinence on working memory neurocircuitry in adolescent daily tobacco smokers. Psychopharmacology (Berl) 2007; 193:557-566.

56. Caspers K, Arndt S, Yucuis R, et al. Effects of alcohol- and cigarette-use disorders on global and specific measures of cognition in middle-age adults. J Stud Alcohol Drugs $2010 ; 71: 192-200$.

57. Razani J, Boone K, Lesser I, et al. Effects of cigarette smoking history on cognitive functioning in healthy older adults. Am J Geriatr Psychiatry 2004; 12:404-411.

58. Schinka JA, Vanderploeg RD, Rogish M, et al. Effects of the use of alcohol and cigarettes on cognition in elderly adults. J Int Neuropsychol Soc 2002; 8:811-818. 
59. Glass JM, Buu A, Adams KM, et al. Effects of alcoholism severity and smoking on executive neurocognitive function. Addiction 2009; 104:38-48.

60. Fisk JE, Montgomery C. Sleep impairment in ecstasy/polydrug and cannabis-only users. Am J Addict 2009; 18: 430-437.

61. Montgomery C, Fisk JE. Everyday memory deficits in ecstasy-polydrug users. $J$ Psychopharmacol 2007; 21:709-717. 
TABLE 1. Demographic Variables for Current and Previous Ecstasy/Polydrug Users and Non-users

\begin{tabular}{|c|c|c|c|c|c|c|c|c|c|c|}
\hline & \multicolumn{3}{|c|}{$\begin{array}{c}\text { Current } \\
\text { Ecstasy/Polydrug } \\
\text { Users }\end{array}$} & \multicolumn{3}{|c|}{$\begin{array}{c}\text { Previous } \\
\text { Ecstasy/Polydrug } \\
\text { Users }\end{array}$} & \multicolumn{3}{|c|}{$\begin{array}{c}\text { Non-users of } \\
\text { Ecstasy }\end{array}$} & \multirow[t]{2}{*}{$P^{\mathrm{a}}$} \\
\hline & Mean & SD & $\mathrm{N}$ & Mean & SD & $\mathrm{n}$ & Mean & SD & $\mathrm{n}$ & \\
\hline Age (y) & 21.05 & 2.00 & 42 & 22.33 & 4.23 & 18 & 21.14 & 2.90 & 50 & NS \\
\hline $\begin{array}{l}\text { Raven's Progressive } \\
\text { Matrices (maximum 60) }\end{array}$ & 44.34 & 8.66 & 42 & 39.33 & 7.62 & 18 & 43.34 & 7.77 & 50 & NS \\
\hline Education $(\mathrm{y})$ & 15.12 & 3.35 & 41 & 14.56 & 3.63 & 18 & 14.92 & 2.63 & 50 & NS \\
\hline Cigarettes (per day) & 7.44 & 4.26 & 16 & 12.40 & 11.07 & 10 & 7.38 & 5.99 & 13 & NS \\
\hline Alcohol (units per week) & 15.76 & 11.10 & 42 & 9.82 & 6.26 & 17 & 9.28 & 9.76 & 47 & 0.007 \\
\hline
\end{tabular}

${ }^{\mathrm{a}}$ For one-way analysis of variance.

SD indicates standard deviation; NS, not significant. 
TABLE 2. Background Drug Use for Current and Previous Ecstasy/Polydrug Users and Non-users

\begin{tabular}{|c|c|c|c|c|c|c|c|c|c|c|c|c|c|}
\hline & \multicolumn{4}{|c|}{ Current Ecstasy/Polydrug Users } & \multicolumn{4}{|c|}{ Previous Ecstasy/Polydrug Users } & \multicolumn{4}{|c|}{ Non-users of Ecstasy } & \multirow[t]{2}{*}{$P^{\mathrm{a}}$} \\
\hline & Median & Mean & SD & $\mathrm{n}$ & Median & Mean & SD & $\mathrm{n}$ & Median & Mean & $\mathrm{SD}$ & $\mathrm{n}$ & \\
\hline \multicolumn{14}{|l|}{ Total lifetime use } \\
\hline Ecstasy (tablets) & 221 & 750.29 & 1293.51 & 42 & 149 & 395.44 & 885.49 & 18 & - & - & - & 0 & NS \\
\hline Cannabis (joints) & 900 & 3358.11 & 4883.61 & 37 & 572 & 2709.88 & 5205.16 & 16 & 192 & 1578.47 & 2928.16 & 17 & NS \\
\hline Cocaine (lines) & 436 & 1131.47 & 1596.75 & 30 & 108 & 746.78 & 929.41 & 9 & - & - & - & 0 & NS \\
\hline \multicolumn{14}{|l|}{$\begin{array}{l}\text { Current frequency of } \\
\text { use (times per week) }\end{array}$} \\
\hline Ecstasy & 0.25 & 0.35 & 0.40 & 42 & 0 & 0 & 0 & 18 & - & - & - & 0 & - \\
\hline Cannabis & 0.50 & 1.65 & 2.35 & 37 & 0.05 & 1.03 & 2.12 & 16 & 0.04 & 1.52 & 2.55 & 17 & NS \\
\hline Cocaine & 0.25 & 0.38 & 0.44 & 30 & 0.02 & 0.15 & 0.35 & 8 & - & - & - & 0 & NS \\
\hline \multicolumn{14}{|l|}{ Weeks since last use } \\
\hline Ecstasy & 3 & 5.71 & 6.24 & 42 & 52 & 105.33 & 92.69 & 18 & - & - & - & 0 & $<0.00$ \\
\hline Cannabis & 1 & 15.27 & 40.70 & 38 & 24 & 34.19 & 42.52 & 15 & 12 & 72.44 & 103.77 & 17 & 0.010 \\
\hline Cocaine & 2 & 9.63 & 15.21 & 35 & 16 & 30.09 & 31.65 & 10 & - & - & - & 0 & 0.006 \\
\hline \multicolumn{14}{|l|}{ Weeks since first use } \\
\hline Ecstasy & 156 & 182.31 & 121.46 & 42 & 223 & 252.94 & 145.27 & 18 & - & - & - & 0 & NS \\
\hline Cannabis & 260 & 304.45 & 142.53 & 38 & 296 & 382.13 & 272.67 & 15 & 308 & 323.53 & 219.23 & 17 & NS \\
\hline Cocaine & 122 & 161.83 & 113.91 & 35 & 260 & 255.64 & 134.62 & 11 & - & - & - & 0 & 0.027 \\
\hline
\end{tabular}

${ }^{\mathrm{a}}$ For one-way analysis of variance, comparing current and previous ecstasy users for cocaine and ecstasy, and all 3 groups for cannabis.

NS indicates not significant. 
TABLE 3. Outcomes on the Self-Report BRIEF-A for Current and Previous Ecstasy/Polydrug Users and Non-users

\begin{tabular}{|c|c|c|c|c|c|c|c|c|c|c|c|}
\hline \multirow[t]{2}{*}{ BRIEF-A Subscale } & \multicolumn{2}{|c|}{$\begin{array}{c}\text { Current } \\
\text { Ecstasy/Polydrug } \\
\text { Users }(\mathrm{n}=42)\end{array}$} & \multicolumn{2}{|c|}{$\begin{array}{c}\text { Previous } \\
\text { Ecstasy/Polydrug } \\
\text { Users }(\mathrm{n}=18)\end{array}$} & \multicolumn{2}{|c|}{$\begin{array}{c}\text { Non-users of } \\
\text { Ecstasy } \\
(\mathrm{n}=50)\end{array}$} & \multicolumn{2}{|c|}{$\begin{array}{l}\text { Overall Effect: }^{\text {a }} \\
\text { F }(2,101)\end{array}$} & \multicolumn{3}{|c|}{ Pairwise Comparisons: $P^{\mathrm{b}}$} \\
\hline & Mean & SD & Mean & SD & Mean & SD & $P$ & Partial $\eta^{2}$ & $\begin{array}{l}\text { Current vs } \\
\text { Non-user }\end{array}$ & $\begin{array}{r}\text { Current vs } \\
\text { Previous }\end{array}$ & $\begin{array}{r}\text { Non-user } \\
\text { vs Previous }\end{array}$ \\
\hline Inhibit & 16.29 & 2.22 & 13.94 & 3.61 & 13.88 & 2.81 & $<0.001$ & .208 & $<0.001$ & $<0.001$ & NS \\
\hline Shift & 9.79 & 2.40 & 10.17 & 2.96 & 9.76 & 2.26 & NS & & & & \\
\hline Emotional Control & 17.02 & 4.71 & 17.11 & 3.77 & 17.52 & 4.56 & NS & & & & \\
\hline Self-Monitor & 10.86 & 2.55 & 9.50 & 2.83 & 9.22 & 2.05 & 0.001 & .134 & 0.003 & 0.001 & NS \\
\hline Initiate & 15.60 & 2.95 & 13.67 & 3.45 & 13.42 & 2.52 & $<0.001$ & .142 & 0.001 & 0.001 & NS \\
\hline Working Memory & 15.05 & 3.04 & 14.17 & 4.09 & 13.52 & 2.81 & 0.010 & .088 & 0.007 & 0.015 & NS \\
\hline Plan/Organize & 18.48 & 4.33 & 16.22 & 4.33 & 15.88 & 3.19 & 0.007 & .093 & 0.007 & 0.010 & NS \\
\hline Task Monitor & 11.76 & 2.40 & 10.44 & 2.31 & 10.20 & 1.80 & 0.001 & .125 & 0.002 & 0.002 & NS \\
\hline $\begin{array}{l}\text { Organization of } \\
\text { Materials }\end{array}$ & 15.74 & 4.03 & 13.17 & 3.64 & 13.08 & 3.69 & 0.007 & .093 & 0.013 & 0.005 & NS \\
\hline
\end{tabular}

${ }^{a}$ For analysis of covariance with drug use between participants and units of alcohol per week and cigarettes per day as covariates. One previous user and 3 non-users did not provide values for the covariates.

${ }^{b}$ For least significant differences without adjustment for multiple comparisons.

BRIEF-A indicates Behavior Rating Inventory of Executive Function-Adult Version; SD, standard deviation; NS, not significant. 
TABLE 4. Regression Analyses with the BRIEF-A Subscales as Dependent Variables and Drug Use Patterns as Predictors

\begin{tabular}{|c|c|c|c|c|c|c|c|c|c|c|c|}
\hline \multirow[t]{3}{*}{ BRIEF-A Subscale } & \multicolumn{6}{|c|}{ Current Frequency of Use for: } & \multirow{2}{*}{\multicolumn{2}{|c|}{ Cigarettes per Day }} & \multirow{2}{*}{\multicolumn{2}{|c|}{ Alcohol (Units per Week) }} & \multirow[t]{2}{*}{$\mathrm{R}^{2}$} \\
\hline & \multicolumn{2}{|c|}{ Ecstasy } & \multicolumn{2}{|c|}{ Cannabis } & \multicolumn{2}{|c|}{ Cocaine } & & & & & \\
\hline & $\mathrm{B}$ & $\begin{array}{l}\text { r: Simple/ } \\
\text { Semi-partial }\end{array}$ & B & $\begin{array}{l}\text { r: Simple/ } \\
\text { Semi-partial }\end{array}$ & $\beta$ & $\begin{array}{l}\text { r: Simple/ } \\
\text { Semi-partial }\end{array}$ & $\beta$ & $\begin{array}{l}\text { r: Simple/ } \\
\text { Semi-partial }\end{array}$ & $\beta$ & $\begin{array}{l}\text { r: Simple/ } \\
\text { Semi-partial }\end{array}$ & \\
\hline Inhibit & & $.337 * * *$ & & .110 & & $.266^{* *}$ & & $.367 * * *$ & & $.235^{*}$ & \\
\hline & .322 & $.271 * *$ & -.115 & -.103 & .040 & .035 & .356 & $.340 * * *$ & .183 & .177 & $.280 * * *$ \\
\hline Shift & & .027 & & -.012 & & -.047 & & $.248 * *$ & & -.112 & \\
\hline & .107 & .090 & -.083 & -.074 & -.121 & -.105 & .291 & $.278^{* *}$ & -.111 & -.107 & .094 \\
\hline Emotional Control & & .080 & & .036 & & -.081 & & $.255^{* *}$ & & -.094 & \\
\hline & .181 & .152 & -.062 & -.055 & -.192 & -.167 & .302 & $.289 * *$ & -.095 & -.092 & .114 \\
\hline Self-Monitor & & $.319 * * *$ & & .156 & & $.237 *$ & & $.366^{* * *}$ & & $.227 *$ & \\
\hline & .292 & $.246 * *$ & -.054 & -.048 & .025 & .022 & .347 & $.332 * * *$ & .170 & .164 & $.257 * * *$ \\
\hline Initiate & & $.277 * *$ & & $.198 *$ & & $.195^{*}$ & & $.193^{*}$ & & $.171 *$ & \\
\hline & .209 & .176 & .070 & .062 & .059 & .051 & .150 & .143 & .109 & .105 & $.130 *$ \\
\hline Working Memory & & .143 & & .162 & & .119 & & $.279 * *$ & & .084 & \\
\hline & .094 & .079 & .067 & .060 & .026 & .022 & .253 & $.242 *$ & .034 & .033 & .101 \\
\hline Plan/Organize & & $.257 * *$ & & .133 & & $.228 *$ & & $.264 * *$ & & $.286 * *$ & \\
\hline & .207 & .174 & -.039 & -.035 & .060 & .052 & .234 & $.223 *$ & .240 & $.232 *$ & $.192 * *$ \\
\hline Task Monitor & & $.249 * *$ & & .077 & & .132 & & $.218^{*}$ & & $.185^{*}$ & \\
\hline & .271 & $.228^{*}$ & -.094 & -.084 & -.046 & -.040 & .222 & $.212 *$ & .161 & .155 & $.133^{*}$ \\
\hline Organization of & & .103 & & .094 & & .098 & & $.284 * *$ & & $.216^{*}$ & \\
\hline Materials & .088 & .074 & -.034 & -.031 & -.020 & -.018 & .276 & $.264 * *$ & .193 & .187 & $.124 *$ \\
\hline Behavior Regulation & & $.236^{*}$ & & .090 & & .100 & & $.390 * * *$ & & .065 & \\
\hline Index & .289 & $.243 *$ & -.100 & -.089 & -.097 & -.085 & .414 & $.396^{* * *}$ & .034 & .033 & $.213 * * *$ \\
\hline Metacognition Index & & $.235^{*}$ & & .156 & & $.183^{*}$ & & $.297 * *$ & & $.230^{*}$ & \\
\hline & .194 & .163 & -.007 & -.006 & .022 & .019 & .271 & $.259 * *$ & .182 & .176 & $.171 * *$ \\
\hline Global Executive & & $.257 * *$ & & .142 & & .164 & & $.366^{* * *}$ & & $.180 *$ & \\
\hline Composite & .254 & $.214^{*}$ & -.048 & -.043 & -.028 & -.024 & .360 & $.343 * * *$ & .134 & .130 & $.210 * * *$ \\
\hline
\end{tabular}

$* P<0.05 ; * * P<0.01 ; * * * P<0.001$.

BRIEF-A indicates Behavior Rating Inventory of Executive Function-Adult Version. 
TABLE 5. Correlations Between BRIEF-A Subscales and Abstinence Duration and Recent Use of Ecstasy, Cannabis, and Cocaine

\begin{tabular}{|c|c|c|c|c|c|c|}
\hline \multirow[t]{2}{*}{ BRIEF-A Subscale } & \multicolumn{3}{|c|}{ Weeks Since Last Use } & \multicolumn{3}{|c|}{ Use in the Past 10 Days } \\
\hline & $\begin{array}{l}\text { Ecstasy } \\
(\mathrm{n}=60)\end{array}$ & $\begin{array}{l}\text { Cannabis } \\
(\mathrm{n}=70)\end{array}$ & $\begin{array}{l}\text { Cocaine } \\
(\mathrm{n}=45)\end{array}$ & $\begin{array}{l}\text { Ecstasy } \\
(\mathrm{n}=60)\end{array}$ & $\begin{array}{l}\text { Cannabis } \\
(\mathrm{n}=72)\end{array}$ & $\begin{array}{l}\text { Cocaine } \\
(\mathrm{n}=46)\end{array}$ \\
\hline Inhibit & $-.527 * * *$ & -.159 & -.247 & .162 & .076 & -.007 \\
\hline Shift & -.216 & .092 & .003 & .064 & .049 & -.063 \\
\hline Emotional Control & -.104 & .132 & -.066 & .129 & $.303 * *$ & -.004 \\
\hline Self-Monitor & $-.314 *$ & -.044 & -.228 & .162 & .113 & .035 \\
\hline Initiate & $-.394 * *$ & -.187 & -.208 & .113 & .067 & -.002 \\
\hline Working Memory & $-.332 * *$ & -.015 & -.184 & .004 & .080 & -.051 \\
\hline Plan/Organize & $-.325^{*}$ & -.166 & -.252 & .100 & .192 & -.050 \\
\hline Task Monitor & $-.377 * *$ & -.144 & -.173 & -.013 & .154 & -.141 \\
\hline $\begin{array}{l}\text { Organization of } \\
\text { Materials }\end{array}$ & $-.302 *$ & -.184 & -.144 & .081 & .146 & -.103 \\
\hline $\begin{array}{l}\text { Behavior Regulation } \\
\text { Index }\end{array}$ & $-.329 *$ & .025 & -.152 & .159 & .192 & -.011 \\
\hline Metacognition Index & $-.403 * *$ & -.170 & -.235 & .075 & .157 & -.079 \\
\hline $\begin{array}{l}\text { Global Executive } \\
\text { Composite }\end{array}$ & $-.395 * *$ & -.093 & -.215 & .116 & .182 & -.055 \\
\hline
\end{tabular}

$* P<0.05 ; * * P<0.01 ; * * * P<0.001$.

BRIEF-A indicates Behavior Rating Inventory of Executive Function-Adult Version. 
TABLE 6. Correlations Between BRIEF-A Subscales and Other Measures of RealWorld Memory ${ }^{\mathrm{a}}$

\begin{tabular}{|c|c|c|c|c|c|c|c|}
\hline BRIEF-A Subscale & $\begin{array}{l}\text { CFQ for } \\
\text { Others } \\
(\mathrm{n}=44)\end{array}$ & CFQ & $\begin{array}{l}\text { CFQ Controlling for Everyday } \\
\text { Memory and Crawford's } \\
\text { PRMQ RM Subscale }\end{array}$ & $\begin{array}{l}\text { Everyday } \\
\text { Memory }\end{array}$ & $\begin{array}{l}\text { Everyday Memory } \\
\text { Controlling for } \\
\text { CFQ }\end{array}$ & $\begin{array}{l}\text { Crawford's } \\
\text { PRMQ RM } \\
\text { Subscale }\end{array}$ & $\begin{array}{l}\text { Crawford's PRMQ } \\
\text { RM Subscale } \\
\text { Controlling for CFQ }\end{array}$ \\
\hline Inhibit & $.313^{*}$ & $.487 * * *$ & $.386 * * *$ & $.201 *$ & -.121 & $.342 * * *$ & -.024 \\
\hline Shift & .282 & $.422 * * *$ & $.270 * *$ & $.254 *$ & .008 & $.337 * * *$ & .046 \\
\hline Emotional Control & .192 & $.316^{* *}$ & .197 & .119 & -.088 & $.277 * *$ & .071 \\
\hline Self-Monitor & $.361 *$ & $.397 * * *$ & .176 & $.274 * *$ & .055 & $.390 * * *$ & .158 \\
\hline Initiate & $.453 * *$ & $.604 * * *$ & $.340 * * *$ & $.398 * * *$ & .066 & $.562 * * *$ & $.221 *$ \\
\hline Working Memory & $.515 * * *$ & $.638 * * *$ & $.360 * * *$ & $.475 * * *$ & .160 & $.585 * * *$ & $.224^{*}$ \\
\hline Plan/Organize & $.546 * * *$ & $.646^{* * *}$ & $.452 * * *$ & $.401 * * *$ & .035 & $.515^{* * *}$ & .081 \\
\hline Task Monitor & $.500 * * *$ & $.599 * * *$ & $.346 * * *$ & $.374 * * *$ & .034 & $.551 * * *$ & $.207^{*}$ \\
\hline $\begin{array}{l}\text { Organization of } \\
\text { Materials }\end{array}$ & $.532 * * *$ & $.524 * * *$ & $.437 * * *$ & $.231 *$ & -.111 & $.339 * * *$ & -.076 \\
\hline $\begin{array}{l}\text { Behavior } \\
\text { Regulation Index }\end{array}$ & $.351 *$ & $.514 * * *$ & $.342 * * *$ & $.255^{*}$ & -.068 & $.427 * * *$ & .087 \\
\hline $\begin{array}{l}\text { Metacognition } \\
\text { Index }\end{array}$ & $.589 * * *$ & $.710 * * *$ & $.501 * * *$ & $.436 * * *$ & .033 & $.589 * * *$ & .146 \\
\hline $\begin{array}{l}\text { Global Executive } \\
\text { Composite }\end{array}$ & $.542 * * *$ & $.693 * * *$ & $.491 * * *$ & $.399 * * *$ & -.014 & $.575 * * *$ & 139 \\
\hline
\end{tabular}

${ }^{\mathrm{a}} \mathrm{n}=97$ unless otherwise noted

$* P<0.05 ; * * P<0.01 ; * * * P<0.001$.

BRIEF-A indicates Behavior Rating Inventory of Executive Function-Adult Version; CFQ, Cognitive Failures Questionnaire; PRMQ, Prospective and Retrospective Memory Questionnaire; RM, Real-World Memory. 